ISSN 0103-5150

Fisioter. Mov., Curitiba, v. 29, n. 1, p. 173-81, Jan./Mar. 2016

Licenciado sob uma Licença Creative Commons

DOI: http://dx.doi.org.10.1590/0103-5150.029.001.AR02

\title{
Influence of inspiratory muscle training on weaning patients from mechanical ventilation: a systematic review
}

\author{
Influência do treinamento muscular inspiratório no desmame \\ da ventilação mecânica: uma revisão sistemática
}

\author{
Márcia Souza Volpe ${ }^{[a]}$, Andrezza Aparecida Aleixo ${ }^{[b]}$, Pedro Rodrigo Magalhães Negreiros de Almeida ${ }^{[c] *}$ \\ [a] Universidade Federal do Triângulo Mineiro, (UFTM), Uberaba, MG, Brazil \\ [b] Universidade Federal de Uberlândia, (UFU), Uberlândia, MG, Brazil \\ [c] Faculdade Tecsoma (TECSOMA- FATEC), Paracatu, MG, Brazil
}

\begin{abstract}
Introduction: The inability of respiratory muscles to generate force and endurance is recognized as an important cause of failure in weaning patients from invasive mechanical ventilation (IMV). Thus, inspiratory muscle training (IMT) might be an interesting treatment option for patients with prolonged IMV weaning. Objective: The aim of this systematic literature review was to evaluate the effectiveness of inspiratory muscle training in weaning patients from mechanical ventilation and to identify the most effective type of training for this particular purpose. Methods: We searched PubMed, LILACS, PEDro and Web of Science for randomized clinical trials published in English or Portuguese from January 1990 until March 2015. Results: Eighty-nine studies were identified of which five were selected. A total of 267 patients participated in the five randomized clinical trials analyzed here. IMV duration before onset of training varied greatly among subjects. Three studies performed IMT using a threshold device and two studies used adjustments of ventilator pressure sensitivity. Four studies have shown that IMT resulted in a significant increase in inspiratory
\end{abstract}

*MSV: PhD, e-mail: marciasvolpe@gmail.com

AAA: MSc, e-mail: andrezzaleixo@yahoo.com.br

PRMNA: MSc, e-mail: pedro.negreiros2@gmail.com 
maximal pressure. Only two studies, however, have reported that IMT resulted in higher success rates in weaning patients from IMV. One study has found that patients showed a shorter ventilator weaning duration after IMT. Conclusion: IMT using pressure threshold devices results in increased inspiratory muscle strength and can therefore be considered a more effective treatment option and with the potential to optimize ventilator weaning success in patients at risk of prolonged IMV.

Keywords: Artificial respiration. Ventilator weaning. Respiratory muscles.

\section{Resumo}

Introdução: A incapacidade da musculatura respiratória em gerar força e resistência constitui uma importante causa de insucesso no desmame da ventilação mecânica invasiva (VMI). Neste contexto, o treinamento da musculatura inspiratória (TMI) torna-se uma opção de tratamento para pacientes que evoluem com desmame da VMI prolongado. Objetivos: Realizar uma revisão sistemática para avaliar a efetividade do TMI no desmame de pacientes da VMI e identificar a forma de treinamento mais efetivo. Métodos: Foram incluídos apenas ensaios clínicos randomizados, nos idiomas português e/ou inglês, publicados entre janeiro de 1990 e março de 2015. A busca foi realizada nas bases de dados eletrônicas Pubmed, LILACS, PEDro e Web of Science. Resultados: Foram identificados 89 estudos, mas apenas cinco foram selecionados. Participaram dos cinco ensaios randomizados 267 pacientes com tempo de VMI, antes do início do treinamento, diverso. O TMI aplicado foi distinto, dois estudos utilizaram a sensibilidade do ventilador e três estudos, aparelhos com limiar de pressão (threshold). Quatro estudos mostraram que o TMI resultou em aumento da pressão máxima inspiratória. No entanto, apenas dois estudos reportaram que o TMI resultou em maior taxa de sucesso no desmame da VMI e um estudo, em menor tempo de desmame ventilatório. Conclusão: O TMI realizado com aparelhos com limiar de pressão resulta em aumento da força muscular inspiratória e, portanto, pode ser considerado mais efetivo e com potencial para otimizar o desmame de pacientes com risco de VMI prolongada.

Palavras-chave: Ventilação mecânica. Desmame do respirador. Músculos respiratórios.

\section{Introduction}

The imbalance between the endurance and forcegenerating capacity of the inspiratory muscles and the overload imposed on them is an important cause of failure in weaning patients from invasive mechanical ventilation (IMV) $(1,2)$. The failure rate after a spontaneous breathing test (SBT) is reported in the literature to range from $20 \%$ to $43 \%$, depending on the population studied and the criteria used to identify failure in weaning from IMV (3-5). Six to 30 percent of these patients should progress to prolonged weaning, characterized as more than three spontaneous breathing tests or longer than seven days after the first SBT (5-8).

Mechanical ventilatory weaning failure extends patients' time under IMV, leading to an increase in the incidence of morbidity and mortality, in the length of stay in the intensive care unit (ICU) and in hospital costs (9-13). A cohort study conducted in the UK has shown that patients under prolonged IMV were hospitalized 10 days longer and had higher hospital mortality rates than patients who did not receive IMV ( $40.3 \%$ versus 33.8\%) (12). A study conducted in the US with 126 patients receiving prolonged IMV has found that, one year after IMV, only $9 \%$ of survivors $(\mathrm{N}=70)$ were able to independently perform activities of daily living, while $65 \%$ were completely dependent on other people's help (13).

Although respiratory muscle weakness may exist before the institution of ventilatory support or be the result of events/procedures thereafter, there is evidence that the mechanical ventilator alone may adversely affect the structure and function of the diaphragm. This process is called diaphragm dysfunction induced by mechanical ventilaton (DDMV) (14). DDMV seems to be caused by the complete or partial inactivity of the diaphragm, which activates pathophysiological mechanisms that generate rapid loss of 
contractile strength and muscle mass (15). Significant reductions in the cross-sectional area of the diaphragm and increased proteolytic activity have been reported in humans after 18 to 69 hours of controlled IMV (16).

Thus, inspiratory muscle training (IMT), which aims to increase the strength and endurance of the respiratory muscles, might be an interesting nonpharmacological treatment option for patients with history of IMV weaning failure $(11,17)$.

The literature describes different types of IMT in patients who require prolonged IMV. These include: normocapnic or isocapnic hyperpnea, use of devices that add a certain load to the respiratory system, and adjustments of ventilator pressure sensitivity (18).

There are two options of devices for IMT, namely: pressure threshold devices and nonlinear resistors. Pressure threshold devices differ from nonlinear resistors because the load imposed on the respiratory system is independent from the inspiratory flow generated by the patient. Examples of nonlinear resistors are devices that have smaller holes through which the patient breathes $(19,20)$. The inspiratory load imposed on the patient's respiratory system during IMT with nonlinear resistors depends on the inspiratory flow generated by the patient. Thus, it varies according to the breathing pattern adopted by the patient. This makes nonlinear resistors a less advantageous option for IMT $(18,21,22)$.

Although IMT has been available as a therapeutic option for patients who require IMV for over 30 years (23), the first randomized clinical trial with positive results on its effectiveness did not occur until the last five years $(24,25)$.

The aim of this systematic literature review was to evaluate the effectiveness of inspiratory muscle training in weaning patients from mechanical ventilation and to identify the most effective type of training for this particular purpose.

\section{Methods}

This is a systematic literature review.

Search strategy

We searched PubMed, LILACS, PEDro and Web of Science for studies published in English or
Portuguese from January 1990 until March 2015, with the terms: 1) respiratory muscle training; "or" 2) inspiratory muscle training; "and" 3) ventilator weaning; "or" 4) mechanical ventilation; "or" 5) artificial respiration.

\section{Selection of studies}

We included only randomized controlled trials with adults (aged 18 years or older) receiving IMV in which pressure threshold devices (i.e., in which the inspiratory load imposed on the patient's respiratory system did not depend on the generated airflow) or ventilator pressure sensitivity were used in IMT. Studies using other training methods were excluded because training load awareness and control are considered important for the success of IMT and the assessment of its results (21).

Two researchers searched and evaluated the studies independently for inclusion. The selection of articles was performed in several steps: i) the study title was read; ii) the abstract was read; iii) full-text copies of all studies deemed to be potentially relevant were retrieved and a more detailed assessment of the article's fit with the agreed upon inclusion criteria was conducted. Aiming to improve the selection procedure, we also analyzed the references of the studies selected. Disagreements at any step were reconciled through discussion.

The following outcomes were considered for the analysis of the influence of IMT on weaning patients from IMV: maximal inspiratory pressure (PImax), ventilator weaning duration, success rate in weaning IMV, reintubation rate, and length of ICU and hospital stay.

\section{Quality assessment}

Methodological quality was assessed with the PEDro scale, which is available on the PEDro website. The PEDro scale has 11 criteria, with a maximum score of 10 (range $0-10$ ) as the first item (the specification of the eligibility criteria) is not included in the total score (26).

Studies with a score of $\geq 6$ are judged to be of high quality (27). 


\section{Results}

Figure 1 is a flow chart describing the study selection process. The five studies that were included in this review $(24,25,35-37)$ are summarized in Table 1.

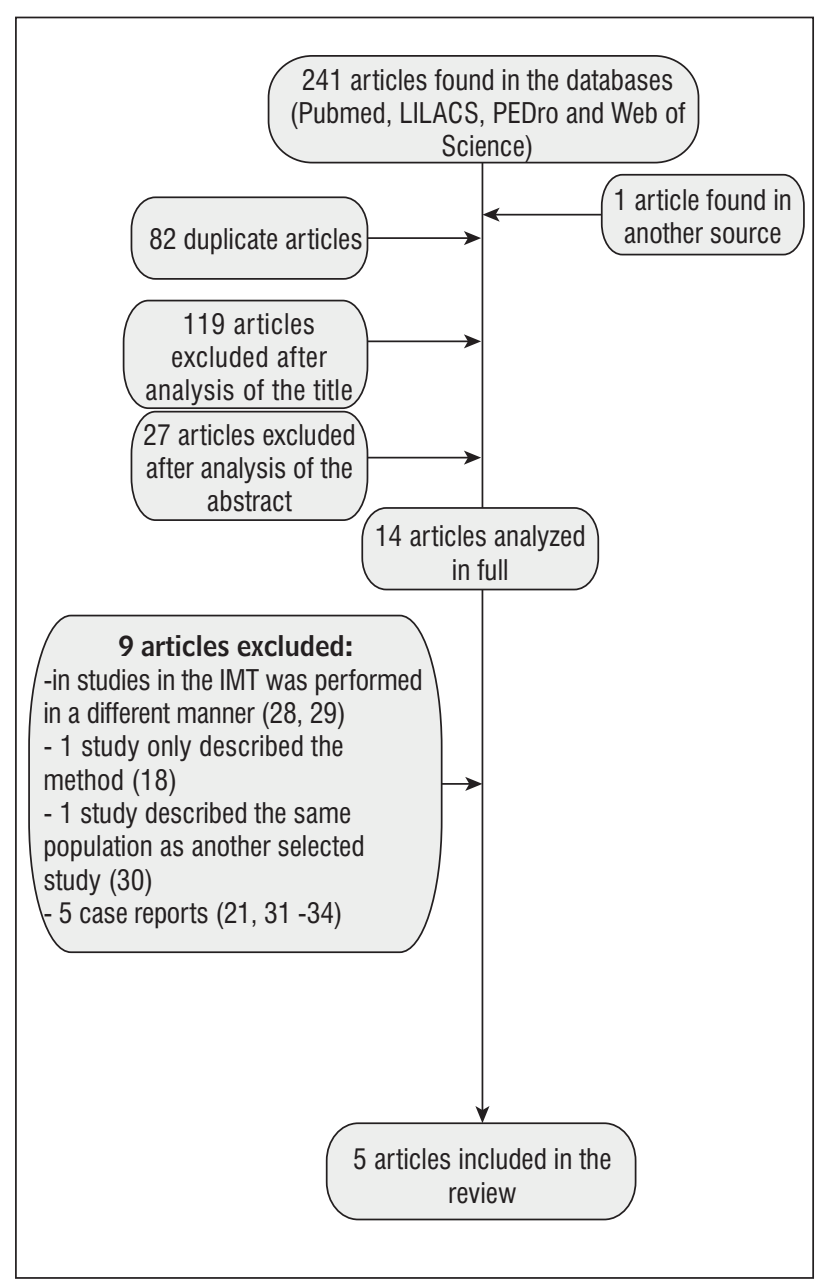

Figure 1 - Flow chart describing the study selection process.

Of the five studies analyzed, only the one conducted by Elbouhy et al. (37) has not been assessed in the PEDro database. This is probably due to the fact that it is not clear in the study whether the selection process was random (randomization is one of the five eligibility criteria for inclusion in the PEDro database). The assessment of methodological quality of the remaining four articles revealed a mean score of 6.3 ( 4 was the lowest score (35) and 8 (25) was the highest score). This indicates that, overall, the studies had high methodological quality.

A total of 267 patients participated in the five clinical trials analyzed here. Respiratory failure was the main cause of orotracheal intubation and onset of IMV. Patients had a mean age of 62 years and IMV duration before onset of training varied greatly among subjects. Three studies performed IMT using a threshold device $(24,25,36)$ and two studies used adjustments of ventilator pressure sensitivity $(35,37)$. The initial training load ranged from $20 \%$ to $40 \%$ of the PImax, except in the study by Martin et al. (25), in which the initial load was the maximum load tolerated by the patient. In the majority of the studies, the IMT was performed twice a day, in fiveminute sessions.

With regard to the main outcomes investigated in the studies, all five studies analyzed the PImax; three studies assessed ventilator weaning duration $(24,35,36)$; two studies evaluated the success rate in weaning MV $(25,37)$; two studies investigated the reintubation rate $(35,36)$; and one study analyzed the length of ICU and hospital stay (37).

Figure 2 illustrates the difference between the mean PImax (measured before and at the end of the intervention) in the control and IMT groups in all five studies. The study by Caruso et al. (35) was the only clinical trial in which the IMT group has shown no increase in PImax.

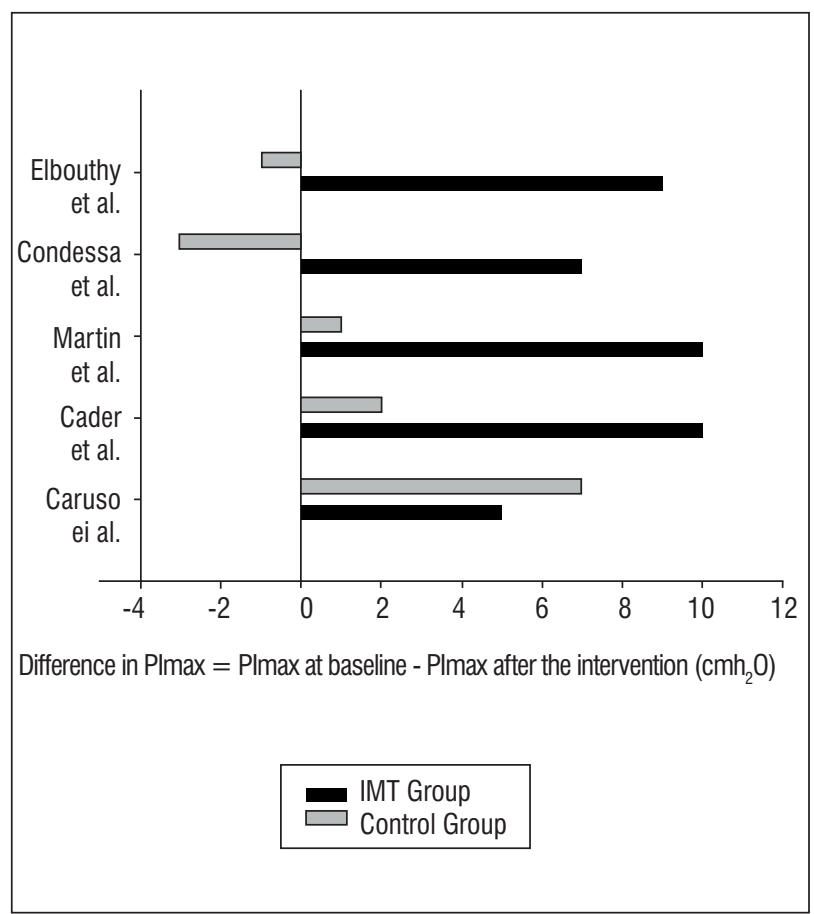

Figure 2 - Difference in PImax (PImax before the intervention - PImax after the intervention) found in the control and inspiratory muscle training (IMT) groups investigated in the five randomized clinical trials. 


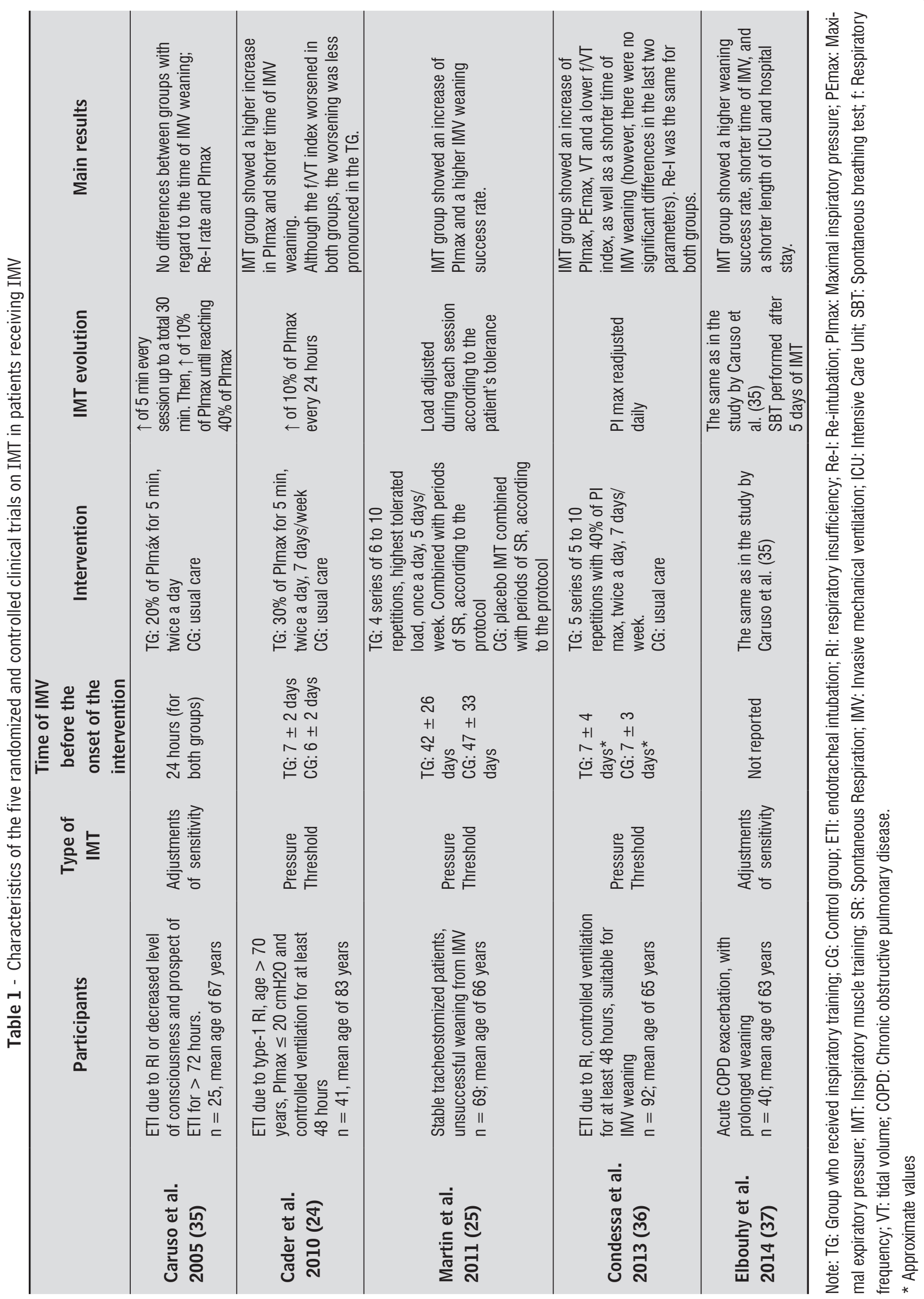


Although most of the studies have shown a significant increase in PImax in the IMT group, only two studies have reported higher success rates in weaning patients from IMV $(25,37)$. One study has found that patients showed a shorter ventilator weaning duration (24) and one study has found that patients had a shorter ICU and hospital stay (37). In the study by Martin et al. (25), 25 of the 35 patients in the IMT group $(71 \%)$ were successfully weaned from IMV, whereas only 16 of the 34 patients in the control group (47\%) had success in this respect. Elbouhy et al. (37) reported a weaning success rate of $90 \%$ (18 out of 20 patients) in the IMT group and of 55\% (11 out of 20 patients) in the control group. In the study by Cader et al. (24), the IMT group was weaned on average 1.7 days faster than the control group. Although Elbouhy et al. (37) have shown that the IMT group had shorter ICU and hospital stay (approximately four days less than the control group), the study had a small number of participants $(\mathrm{N}=40)$, which affects the robustness of this result.

\section{Discussion}

In order to be considered clinically effective, the IMT - regardless of the device used in training - should result in a significant increase in PImax, i.e., enhance the endurance- and force-generating capacity of the inspiratory muscles, and consequently increase the success rate of weaning from IMV and /or decrease the weaning time.

It is also known that respiratory effort perception and respiratory drive are inversely related to the respiratory muscle strength. Thus, the higher the PImax, the weaker the sensation of dyspnea and the lower the respiratory drive $(21,38)$. Therefore, a higher PImax should also facilitate weaning from IMV in patients who are able to maintain adequate gas exchange and minute ventilation but do not tolerate the feeling of difficulty in maintaining the spontaneous breathing effort.

Four of the five studies analyzed here have shown that IMT results in a significant increase in PImax and therefore should be considered as a strategy with potential to optimize the IMV weaning process. Nevertheless, only two studies have found that IMT resulted in higher success rates in weaning patients from IMV $(25,37)$ and only one study has shown that it resulted in a shorter weaning time (24).
Although the five randomized clinical trials investigated here had methodological differences that impaired comparison among them - such as different initial times of IMV, different IMT protocols and use of different primary outcomes - , we concluded that IMT using threshold devices seems to be more effective than IMT using adjustments of ventilator pressure sensitivity. Of the two studies in which training was performed using sensitivity adjustments, one has has found negative results (35) and the other had methodological flaws such as non-randomization of subjects (37).

A first possible explanation for the better results obtained with the use of threshold devices is that during training using these devices the load is imposed on the patient's respiratory system throughout the inspiration, whereas during training using sensitivity adjustments the load is imposed only during the interval between the onset of negative deflection of pressure by the patient and the beginning of the inspiratory flow from the ventilator, i.e., during the triggering of the respiratory cycle. More precisely, the load is imposed during the pre-triggering stage, which ends with the opening of the inspiratory valve (39). Of note, depending on the response time of the inspiratory valve, the duration of training load imposition on the patient's respiratory system may be too short (<100 ms) (40), resulting in a suboptimal training.

A second explanation is that during IMT using sensitivity adjustments if the professional responsible for administering the training does not stay alert all the time, the patient may not provide sufficient inspiratory effort to trigger the respiratory cycle and keep breathing at positive end-expiratory pressure (PEEP). With the use of threshold devices, in order to generate a minimum of tidal volume, the patient necessarily needs the device valve to open (18). Thus, the patient (who does not generate the minimum negative inspiratory pressure necessary to open the valve) will present signs of respiratory distress within a short time after beginning of the training. IMT will then be interrupted and the cause of the distress will be investigated (34).

A third explanation is that the disconnection of the ventilator during IMT using pressure threshold devices - when performed in a controlled manner and close support from a physical therapist - may help patients to control their anxiety and gain confidence in their ability to breathe without the aid of a ventilator (41).

It is important to consider, however, that because the use of threshold devices requires the patient to 
be disconnected from the ventilator, there is a greater risk of hypoxemia and alveolar collapse due to the loss of PEEP $(42,43)$. Hypoxemia may also occur due to the reduction and/or inadequate control of the supply of inspired oxygen during the IMT. Another disadvantage is that the use of threshold devices demands more time from the professional who is administering the IMT.

With regard to the training load, although two studies have used an initial load of $20 \%$ of the PImax $(35,37)$, recent studies state that the initial load should be set to at least $30 \%$ of the PImax to produce force gain (44).

The studies also differed in relation to the beginning of the IMT. While in the study conducted by Caruso et al. (35) the IMT was started within 24 hours of ventilation onset, in the studies by Condessa et al. (36) and Martin et al. (25) the IMT was started after a mean of seven and 45 days of IMV, respectively. Starting from the principle that IMT seems to be indicated for patients who have failed the first spontaneous breathing trial and/or have a suspected DDMV, or who already had diaphragmatic weakness before the institution of IMV, beginning of IMT seems indicated as soon as the patient (who has these characteristics) satifies the criteria established in the literature for onset of weaning from IMV (45).

Future studies should standardize some important points of the IMT protocol, such as the use of pressure threshold devices, minimum initial load of $30 \%$ of the PImax (with load adjustment after every one or two sessions to ensure perceived exertion rated as five/six on a scale of zero to ten), beginning of the IMT as soon as the patient (who is eligible for IMT) is considered ready to start IMV weaning, and training frequency of at least five times a week. In addition to the standardization of IMT protocols, the use of outcomes such as successful ventilator weaning, IMV time and length of ICU and hospital stay should be used in future studies to verify the effectiveness of IMT prior to its adoption in clinical practice.

\section{Conclusion}

IMT, especially when performed using pressure threshold devices, results in increased inspiratory muscle strength (PImax) and is, therefore, a treatment option with the potential to reduce ventilator weaning time and increase the success rate of mechanical ventilation withdrawal.

\section{References}

1. Martin AD, Smith BK, Gabrielli A. Mechanical ventilation, diaphragm weakness and weaning: a rehabilitation perspective. Respir Physiol Neurobiol. 2013;189(2):377-83.

2. Carlucci A, Ceriana P, Prinianakis G, Fanfulla F, Colombo R, Nava S. Determinants of weaning success in patients with prolonged mechanical ventilation. Crit Care. 2009;13(3):R97.

3. Frutos-Vivar F, Esteban A. Weaning from mechanical ventilation: why are we still looking for alternative methods? Med Intensiva. 2013;37(9):605-17.

4. Heunks LM, van der Hoeven JG. Clinical review: the $\mathrm{ABC}$ of weaning failure-a structured approach. Crit Care. 2010;14(6):245.

5. Boles JM, Bion J, Connors A, Herridge M, Marsh B, Melot $\mathrm{C}$, et al. Weaning from mechanical ventilation. Eur Respir J. 2007;29(5):1033-56.

6. Penuelas 0, Frutos-Vivar F, Fernandez C, Anzueto A, Epstein SK, Apezteguia C, et al. Characteristics and outcomes of ventilated patients according to time to liberation from mechanical ventilation. Am J Respir Crit Care Med. 2011;184(4):430-7.

7. Sellares J, Ferrer M, Cano E, Loureiro H, Valencia M, Torres A. Predictors of prolonged weaning and survival during ventilator weaning in a respiratory ICU. Intensive Care Med. 2011;37(5):775-84.

8. Rose L, Dainty KN, Jordan J, Blackwood B. Weaning from mechanical ventilation: a scoping review of qualitative studies. Am J Crit Care. 2014;23(5):e54-70.

9. Esteban A, Anzueto A, Frutos F, Alia I, Brochard L, Stewart TE, et al. Characteristics and outcomes in adult patients receiving mechanical ventilation: a 28day international study. JAMA. 2002;287(3):345-55.

10. Epstein SK. Weaning from ventilatory support. Curr Opin Crit Care. 2009;15(1):36-43.

11. Ambrosino N. Weaning and respiratory muscle dysfunction: the egg-chicken dilemma. Chest. 2005;128(2):481-3. 
12. Lone NI, Walsh TS. Prolonged mechanical ventilation in critically ill patients: epidemiology, outcomes and modelling the potential cost consequences of establishing a regional weaning unit. Crit Care. 2011;15(2):R102.

13. Unroe M, Kahn JM, Carson SS, Govert JA, Martinu T, Sathy SJ, et al. One-year trajectories of care and resource utilization for recipients of prolonged mechanical ventilation: a cohort study. Ann Intern Med. 2010;153(3):167-75.

14. Vassilakopoulos T, Petrof BJ. Ventilator-induced diaphragmatic dysfunction. American journal of respiratory and critical care medicine. 2004;169(3):336-41.

15. Powers SK, Wiggs MP, Sollanek KJ, Smuder AJ. Ventilator-induced diaphragm dysfunction: cause and effect. Am J Physiol Regul Integr Comp Physiol. 2013;305(5):R464-77.

16. Levine S, Nguyen T, Taylor N, Friscia ME, Budak MT, Rothenberg P, et al. Rapid disuse atrophy of diaphragm fibers in mechanically ventilated humans. The New England journal of medicine. 2008;358(13):1327-35.

17. Chang AT, Boots RJ, Brown MG, Paratz J, Hodges PW. Reduced inspiratory muscle endurance following successful weaning from prolonged mechanical ventilation. Chest. 2005;128(2):553-9.

18. Moodie LH, Reeve JC, Vermeulen N, Elkins MR. Inspiratory muscle training to facilitate weaning from mechanical ventilation: protocol for a systematic review. BMC Res Notes. 2011;4:283.

19. Aldrich TK, Karpel JP. Inspiratory muscle resistive training in respiratory failure. Am Rev Respir Dis. 1985;131(3):461-2.

20. Aldrich TK, Karpel JP, Uhrlass RM, Sparapani MA, Eramo D, Ferranti R. Weaning from mechanical ventilation: adjunctive use of inspiratory muscle resistive training. Crit Care Med. 1989;17(2):143-7.

21. Martin AD, Davenport PD, Franceschi AC, Harman E. Use of inspiratory muscle strength training to facilitate ventilator weaning: a series of 10 consecutive patients. Chest. 2002;122(1):192-6.

22. Hill K, Cecins NM, Eastwood PR, Jenkins SC. Inspiratory muscle training for patients with chronic obstructive pulmonary disease: a practical guide for clinicians. Arch Phys Med Rehabil. 2010;91(9):1466-70.
23. Belman MJ. Respiratory failure treated by ventilatory muscle training (VMT). A report of two cases. Eur J Respir Dis. 1981;62(6):391-5.

24. Cader SA, Vale RGD, Castro JC, Bacelar SC, Biehl C, Gomes MCV, et al. Inspiratory muscle training improves maximal inspiratory pressure and may assist weaning in older intubated patients: a randomised trial. J Physiother. 2010;56(3):171-7.

25. Martin AD, Smith BK, Davenport PD, Harman E, Gonzalez-Rothi RJ, Baz M, et al. Inspiratory muscle strength training improves weaning outcome in failure to wean patients: a randomized trial. Crit Care. 2011;15(2):R84.

26. Shiwa SR, Costa LO, Costa Lda C, Moseley A, Hespanhol Junior LC, Venancio R, et al. Reproducibility of the Portuguese version of the PEDro Scale. Cad Saude Publica. 2011;27(10):2063-8.

27. Maher CG, Sherrington C, Herbert RD, Moseley AM, Elkins M. Reliability of the PEDro scale for rating quality of randomized controlled trials. Phys Ther. 2003;83(8):713-21.

28. Sharma R, Narwal R, Kumar S. Comparison of proprioceptive neuromuscular facilitation versus resistance training of respiratory muscles on respiratory rate of patients in ICU during weaning off period. Indian Journal of Physiotherapy and Occupational Therapy. 2010;4(4):125-8.

29. Chang MY, Chang LY, Huang YC, Lin KM, Cheng CH. Chair-sitting exercise intervention does not improve respiratory muscle function in mechanically ventilated intensive care unit patients. Respir Care. 2011;56(10):1533-8.

30. Cader SA, de Souza Vale RG, Zamora VE, Costa CH, Dantas EH. Extubation process in bed-ridden elderly intensive care patients receiving inspiratory muscle training: a randomized clinical trial. Clin Interv Aging. 2012;7:437-43.

31. Bissett $B$, Leditschke IA. Inspiratory muscle training to enhance weaning from mechanical ventilation. Anaesth Intensive Care. 2007;35(5):776-9.

32. Bissett B, Leditschke IA, Green M. Specific inspiratory muscle training is safe in selected patients who are ventilator-dependent: a case series. Intensive Crit Care Nurs. 2012;28(2):98-104. 
33. Chang AT, Boots RJ, Henderson R, Paratz JD, Hodges PW. Case report: inspiratory muscle training in chronic critically ill patients--a report of two cases. Physiother Res Int. 2005;10(4):222-6.

34. Sprague SS, Hopkins PD. Use of inspiratory strength training to wean six patients who were ventilatordependent. Phys Ther. 2003;83(2):171-81.

35. Caruso P, Denari SD, Ruiz SA, Bernal KG, Manfrin GM, Friedrich $\mathrm{C}$, et al. Inspiratory muscle training is ineffective in mechanically ventilated critically ill patients. Clinics (Sao Paulo). 2005;60(6):479-84.

36. Condessa RL, Brauner JS, Saul AL, Baptista M, Silva AC, Vieira SR. Inspiratory muscle training did not accelerate weaning from mechanical ventilation but did improve tidal volume and maximal respiratory pressures: a randomised trial. J Physiother. 2013;59(2):101-7.

37. Elbouhy M, AbdelHalim H, Hashem A. Effect of respiratory muscles training in weaning of mechanically ventilated COPD patients. Egyptian Journal of Chest Diseases and Tuberculosis. 2014;63:679-87.

38. Bell GJ, Syrotuik D, Martin TP, Burnham R, Quinney HA. Effect of concurrent strength and endurance training on skeletal muscle properties and hormone concentrations in humans. Eur J Appl Physiol. 2000;81(5):418-27.
39. Goulet R, Hess D, Kacmarek RM. Pressure vs flow triggering during pressure support ventilation. Chest. 1997;111(6):1649-53.

40. Carvalho CR, Toufen C, Jr., Franca SA. [Mechanical ventilation: principles, graphic analysis and ventilatory modalities]. J Bras Pneumol. 2007;33 Suppl 2S:S54-70.

41. Bissett B, Leditschke IA, Paratz JD, Boots RJ. Respiratory dysfunction in ventilated patients: can inspiratory muscle training help? Anaesthesia and intensive care. 2012;40(2):236-46.

42. Hedenstierna G, Edmark L. The effects of anesthesia and muscle paralysis on the respiratory system. Intensive Care Med. 2005;31(10):1327-35.

43. Duggan M, Kavanagh BP. Pulmonary atelectasis: a pathogenic perioperative entity. Anesthesiology. 2005;102(4):838-54.

44. Bissett BM, Leditschke IA, Paratz JD, Boots RJ. Protocol: inspiratory muscle training for promoting recovery and outcomes in ventilated patients (IMPROVe): a randomised controlled trial. BMJ Open. 2012;2(2):e000813.

45. Barbas CS, Isola AM, Farias AM, Cavalcanti AB, Gama AM, Duarte AC, et al. Brazilian recommendations of mechanical ventilation 2013. Part 2. Rev Bras Ter Intensiva. 2014;26(3):215-39.

Recebido:21/10/2014

Received: 10/21/2014

Aprovado: $17 / 07 / 2015$

Approved: 07/17/2015 
